\title{
Projeto UCA em Tiradentes: significações de duas professoras quanto às tecnologias digitais de informação e comunicação no contexto escolar ${ }^{1}$
}

\section{UCA Project in Tiradentes: meanings of two teachers about digital information and communication technologies in the school context}

\author{
Marcio Roberto de Lima $^{2}$ \\ Silvania Sousa do Nascimento ${ }^{3}$
}

\begin{abstract}
RESUMO
Este artigo enfoca algumas influências do Projeto Um Computador por Aluno (UCA) na apropriação docente das Tecnologias Digitais de Informação e Comunicação (TDIC) e nas práticas pedagógicas. Em campo, foram realizadas entrevistas com duas professoras que partilharam suas impressões e experiências no Projeto UCA em uma escola de Tiradentes (MG) durante o ano de 2011. Devidamente autorizadas, as entrevistas foram gravadas, transcritas e analisadas em um procedimento misto de Análise de Conteúdo (BARDIN, 1977) e - em alguns momentos - Análise Crítica de Discurso. (GEE, 1999, 2001). Com auxílio do software Atlas.ti os dados empíricos foram codificados em unidades de significados que buscaram sintetizar: as condições de infraestrutura tecnológica oportunizadas pelo Projeto UCA; as percepções docentes sobre o Projeto e suas ações de formação; os principais
\end{abstract}

DOI: $10.1590 / 0104-4060.46117$

1 Investigação financiada pela Coordenação de Aperfeiçoamento de Pessoal de Nível Superior (Capes).

2 Universidade Federal de São João Del-Rei. Departamento de Ciências da Educação. São João Del-Rei, Minas Gerais, Brasil. Campus Dom Bosco. Praça Dom Helvécio, nº 74. Dom Bosco. CEP: 36.301-160.E-mail: marcinholima@ufsj.edu.br

3 Universidade Federal de Minas Gerais. Faculdade de Educação. Belo Horizonte, Minas Gerais, Brasil. Campus Pampulha. Av. Antônio Carlos, nº 6.627. CEP: 31.270-90. E-mail: silnascimento@ufmg.br 
impactos culturais vivenciados pelas professoras, além dos desdobramentos associados nas práticas pedagógicas empreendidas com as TDIC. A análise dos dados evidenciou que as ações do Projeto UCA não foram suficientes para estimular a apropriação docente das TDIC, a reconfiguração das práticas pedagógicas e a instauração de uma cultura digital, tendo em vista o baixo aproveitamento do potencial das TDIC associado a um cenário precário para a implantação da política na escola estudada.

Palavras-chave: políticas públicas; cibercultura; tecnologias digitais; prática pedagógica.

\begin{abstract}
This paper focuses on some influences of the Project A Computer for each Student - "Um Computador por Aluno" (UCA) in teaching appropriation of Information and Communication Technologies (ICTs) and pedagogical practices. In the field, interviews were conducted with two teachers who shared their impressions and experience in the UCA project at a school in Tiradentes (MG) during the year 2011. Duly authorized, the interviews were recorded, transcribed and analyzed in a combined procedure of Content Analysis (BARDIN, 1977) and - sometimes - Discourse Analysis. (GEE, 1999, 2001). With the software Atlas.ti, empirical data were structured in units of meaning that systematized: the technological infrastructure conditions of the UCA Project; the teachers perceptions about the project and its training activities; the main cultural impacts experienced by teachers in addition to the associated development in pedagogical practices undertaken with ICT. The data analysis evidenced that the actions of the UCA Project were not enough to stimulate teaching appropriation of ICTs, the reconfiguration of the pedagogical practice and the establishment of a digital culture, having in mind low exploitation of ICT potential associated with a precarious scenario for the implementation of the policy in the studied school.
\end{abstract}

Keywords: public policies; cyberculture; digital technologies; pedagogical practice.

Notadamente, a presença das Tecnologias Digitais de Informação e Comunicação (TDIC) em nosso cotidiano interpõe um novo modus operandi social, que evidencia um movimento contínuo de modernização e de (re)adaptação de nosso modus vivendi. Além de novas formas comunicativas e de novos hábitos de produção e consumo de informações, experienciamos reconfigurações nas relações socioculturais, econômicas, políticas, etc., todas mediadas pelas TDIC. Esse continuum de inovações e as transformações associadas tipificam a cultura contemporânea, também dita cibercultura (LEMOS, 2003, 2008; LÉVY, 1999) 
ou ainda cultura digital. (LEMOS, 2009; LEMOS; LÉVY, 2010). Para além da utilização de artefatos digitais, a cibercultura abarca apropriação social das tecnologias: o que modifica comportamentos.

Hodiernamente, a educação também é impelida às reconfigurações e precisa se compatibilizar à cibercultura. Para tanto, além do indispensável aparelhamento das escolas para o trabalho com as TDIC, torna-se fundamental a (re)adequação da intencionalidade pedagógica. Compreende-se que essa reconfiguração pedagógica envolve estratégias que valorizam: os processos de autoria discente com TDIC; a exploração do potencial comunicativo com tecnologias digitais; e o compartilhamento/apreciação de produções (individuais e coletivas) em rede. Neste sentido, as políticas públicas de inclusão digital pelo viés escolar assumem importante papel na aproximação da escola do contexto contemporâneo.

Fruto do recorte de uma pesquisa de doutorado, que investigou desdobramentos de políticas públicas de inclusão digital nas práticas pedagógicas, este artigo enfoca algumas influências do Projeto Um Computador por Aluno (UCA) na apropriação docente das TDIC e nas práticas pedagógicas. O período coberto pela investigação compreendeu os anos entre 2007 e 2011, contando com a colaboração de duas professoras da rede de educação pública Municipal de Tiradentes (MG), que trabalharam na vigência do Projeto UCA naquela cidade.

Bárbara e Lucy - nomes fictícios - foram professoras colaboradoras da pesquisa. A professora Bárbara graduou-se em Pedagogia no ano de 2002 e tem duas especializações: uma em Educação Especial com ênfase em Inclusão e outra em Práticas de Letramento e Alfabetização. Bárbara trabalhou como professora efetiva na Escola Beta (nome fictício) com os alunos no $5^{\circ}$ ano do Ensino Fundamental durante o ano de 2011. Lucy também é pedagoga. Formada desde 2008 fez especialização em Design Instrucional Virtual em Educação a Distância. Efetiva na Escola Beta, a professora Lucy trabalhou com a turma do $4^{\circ}$ período do Ensino Fundamental, também no ano de 2011.

A Escola Beta é localizada no centro da cidade de Tiradentes (MG), é vinculada à Rede Municipal de Educação e funciona diuturnamente com duas turmas de Educação Infantil e doze turmas dos anos iniciais do Ensino Fundamental. A escola conta com quatorze docentes, uma assistente educacional, uma diretora, uma vice-diretora, oito auxiliares de serviços gerais, uma supervisora e duas professoras eventuais. O prédio de funcionamento da Escola Beta é uma construção antiga, com dez salas de aula, sendo uma delas ocupada pelo seu laboratório de informática, uma sala para a diretoria e professores, cinco banheiros de uso discente e um de uso docente, uma cozinha, um pátio interno e um parquinho. A Escola Beta não tem boas condições de acessibilidade, não sendo adaptada para pessoas com deficiência física. O público atendido é 
de aproximadamente 305 alunos, filhos de trabalhadores da construção civil, domésticas, diaristas, pequenos comerciantes locais, funcionários públicos, autônomos e desempregados. (ESCOLA MUNICIPAL, 2011)4.

No campo empírico, o caminho metodológico da investigação teve como principal instrumento de coleta de dados a entrevista semiestruturada. Depois de gravado, o material coletado foi transcrito e analisado em um procedimento misto de Análise de Conteúdo (BARDIN, 1977) e - em alguns momentos Análise Crítica de Discurso (GEE, 1999, 2001), gerando um sistema codificado em unidades de significado relacionadas aos objetivos da pesquisa com o auxílio do software Atlas.ti.

A partir da análise das contribuições das colaboradoras, sintetizam-se aqui: as condições de infraestrutura tecnológica oportunizadas pelo Projeto UCA na Escola Beta; as percepções docentes sobre o Projeto e suas ações de formação; os principais impactos culturais vivenciados pelas professoras e os desdobramentos associados nas práticas pedagógicas empreendidas com as TDIC.

\section{Significações do Projeto UCA em Tiradentes}

Para a estruturação dos dados de pesquisa para a Análise de Conteúdo, no software Atlas.ti, foram definidos seis códigos ${ }^{5}$, conforme o Quadro 1.

\section{Condições materiais do Projeto UCA}

Com o código "Condições materiais do Proj_UCA", no Atlas.ti, foram sistematizadas as contribuições de Bárbara e Lucy relacionadas à infraestrutura tecnológica relacionada ao Projeto UCA, bem como as impressões das docentes que indicavam as influências daquela infraestrutura no desenvolvimento da cultura digital na Escola Beta. A professora Bárbara destacou contratempos envolvendo a logística do uso dos laptops e seus locais de armazenamento:

4 Referência apresentada de maneira a preservar o anonimato da escola que serviu de contexto para a pesquisa.

5 O ATLAS.ti trata "categorias" como "códigos" (codes), ou seja: unidades de interesse confluentes aos objetivos da pesquisa. No texto assume-se a tradução "código" como sinônimo de "categoria". 
QUADRO 1 - CÓDIGOS CRIADOS NO ATLAS.TI

\begin{tabular}{|l|l|}
\hline \multicolumn{1}{|c|}{ Código utilizado } & \multicolumn{1}{c|}{ Descrição } \\
\hline $\begin{array}{l}\text { Condições materiais } \\
\text { do Proj_UCA }\end{array}$ & $\begin{array}{l}\text { Código associado aos registros das impressões docentes sobre a } \\
\text { infraestrutura tecnológica relacionada ao Projeto UCA. }\end{array}$ \\
\hline $\begin{array}{l}\text { Formação para o } \\
\text { Proj_UCA }\end{array}$ & $\begin{array}{l}\text { Código destinado a identificar como se deu o processo de formação } \\
\text { dos professores para o Projeto UCA e experiências associadas. }\end{array}$ \\
\hline Impacto cultural & $\begin{array}{l}\text { Código para o registro dos desdobramentos do Projeto UCA na } \\
\text { atitude pedagógica dos docentes. }\end{array}$ \\
\hline $\begin{array}{l}\text { Prática pedagógica } \\
\text { com TDIC }\end{array}$ & Código para a catalogação das experiências de trabalho com TDIC. \\
\hline $\begin{array}{l}\text { Reconfiguração da } \\
\text { prática pedagógica }\end{array}$ & $\begin{array}{l}\text { Código que identifica as reconfigurações do trabalho pedagógico } \\
\text { enfatizando o uso do laptop educacional conectado e associado } \\
\text { à produção discente. Reflete experiências que transcenderam o } \\
\text { paradigma tradicional de ensino. }\end{array}$ \\
\hline $\begin{array}{l}\text { Desenvolvimento } \\
\text { da cultura digital na } \\
\text { escola }\end{array}$ & $\begin{array}{l}\text { Código destinado a identificar desdobramentos do Projeto UCA } \\
\text { na escola, indiciando a formação de uma cultura digital no âmbito } \\
\text { escolar. }\end{array}$ \\
\hline
\end{tabular}

FONTE: Autores (2016).

[...] os armários ficavam abertos, tinha em cada sala um armário aberto e ficavam as máquinas lá. O que é ruim: duas turmas usavam em uma mesma sala. Eu estava lecionando numa sala, vinha menino de outra sala pra guardar o laptop dele ali naquele espaço. [...] E aí tinha que ficar indo na sala de outro professor. [Isso] foi determinante para o pouco uso da ferramenta. Porque você tinha de ficar interrompendo a outra professora [...]. (Bárbara, grifos nossos).

Além dessas particularidades, a professora Lucy registrou outro ponto básico que merecia atenção e planejamento prévio do ponto de vista de estruturação do Projeto UCA: “[...] Porque nós, quando a gente foi usar, nem tomada tinha... Pra conectar todos os computadores [...]". E mediante aquela situação, Lucy assumiu que eram as professoras que tinham "[...] que criar as [...] estratégias pra viabilizar a política", concluindo que "[...] não tinha uma política pública ali pra respaldar o uso [das TDIC] [...]." (Lucy, grifos nossos).

Com essas indicações, nota-se que o planejamento e a implementação estrutural - que precisaria preceder à chegada das tecnologias digitais na escola - foram ignorados. Ainda envolvendo as questões materiais do Projeto UCA, outro fator preponderante e que influenciou o destino dos laptops do UCA diz respeito à precária manutenção dos equipamentos: 
[...] Então, quando a Escola começa a se organizar, meio capenga ainda, para guardar o equipamento certinho, eles esbarram com a questão da manutenção. Porque a Prefeitura não tinha um convênio sério e assim... Rigoroso... Com as pessoas para reparar as máquinas com problema. Então vinha alguém que era da Prefeitura, depois fizeram contato com estagiário, de modo que chegou num limite que não tinha mais jeito de fazer o reparo nas máquinas e elas estão lá: sem uso [...]. (Bárbara, grifos nossos).

Em conformidade, Lucy expressou que o Projeto UCA

[...] foi morrendo aos poucos pela falta de manutenção técnica dos computadores. Foi... Foi o pior. Porque a internet não funcionava num dia, funcionava no outro?! A gente dava um jeito de usar. Mas os computadores todos estragados, como que nós íamos usar? Não tem como! [...]. (Lucy, grifos nossos).

Na busca da compreensão de como esses fatores influenciaram o desenvolvimento da cultura digital na Escola Beta, considerou-se que um processo de inclusão digital precisa transcender o mero aparelhamento e o uso instrumental de artefatos tecnológicos. Apesar de necessária, acreditar que a disponibilização de equipamentos seja capaz de promover reconfiguração de práticas nas escolas é conferir às tecnologias um poder determinístico que elas não possuem.

Assim, os problemas relativos à infraestrutura material vivenciados pelas professoras constituíram-se como empecilhos, que contribuíram para a insatisfação frente à proposta de incorporação dos laptops na rotina escolar. Esses mesmos obstáculos também foram indicados por Sandholtz, Ringstaff e Dwyer (1997, p. 149) como "barreiras à mudança" de atitude pedagógica com tecnologias. Dessa forma, compreendeu-se que o quadro das condições materiais do Projeto UCA em Tiradentes indiciou precariedades, afetando negativamente o desenvolvimento da cultura digital na Escola Beta.

\section{Formação para o Projeto UCA}

Antes de apresentar as contribuições de Bárbara e Lucy sobre a formação dos professores de Tiradentes para o Projeto UCA, cabe o registro de que essa 
ação esteve sob a responsabilidade de uma equipe de uma universidade particular de Minas Gerais. Intitulada "Formação Brasil", a ação estruturou-se em duas etapas ${ }^{6}$ : uma presencial e outra on-line. Bernardes (2012) registrou alguns dados sobre a adesão às ações de formação:

Sobre os cursos de formação presencial e online para o uso do laptop UCA aplicado pela [universidade responsável], 70\% dos professores participaram do curso presencial e 30\% não participaram. [...] Em relação ao curso online, apenas uma professora [de uma amostra de 16 docentes] afirmou estar participando ainda do curso, o restante não se inscreveu ou desistiu. [...]. (BERNARDES, 2012, p. 30, grifo nosso).

Pelos números sistematizados acima, constata-se a baixa adesão docente às ações de formação para o uso do laptop educacional, especialmente em sua segunda etapa (a de maior carga horária). Outro fato constitui-se decisivo no contexto da formação docente para o Projeto UCA: em 2011 houve a efetivação de novos professores na rede municipal (devido a um concurso de 2010), o que promoveu a substituição daqueles (poucos) que, eventualmente, haviam começado o processo formativo. Assim, a maioria dos professores que atuaram durante a vigência do Projeto UCA em Tiradentes não foi formada para tal.

Esclarecendo o contexto apresentado, a professora Bárbara ressaltou que:

[...] A gente, recém-chegado de um concurso que foi realizado lá em 2010, nós não passamos nem pela [formação] inicial. [...] O único contato que a gente teve foi uma explanação no inicio do ano letivo, depois deram uma apostila. Mas nada especifico de como funcionava, como deveria ser e qual que era o trabalho que deveria ser feito ali. [...]. (Bárbara, grifo nosso).

6 A formação presencial teve duração de 40 horas e ocorreu em Tiradentes no período de 05/07/2010 a 16/07/2010. Essa etapa compreendeu a chamada "apropriação tecnológica", e seu objetivo foi "permitir ao pessoal um domínio sobre o Classmate, o laptop do Projeto UCA". A etapa contou com 78 participantes, entre professores, gestores e técnicos do Núcleo de Tecnologia Municipal. (MARINHO, 2010). Os materiais utilizados foram o Formação Brasil (2014a e b). A segunda etapa do Formação Brasil foi disponibilizada on-line, entre os dias 20/09 e 22/12/2010, com carga horária de 140 horas e compreendeu: conteúdos sobre "WEB 2.0" - 30 horas, "Formação de professores e de gestores" - 40 horas, "Elaboração de projetos" - 40 horas e "Projeto de Gestão Integrada da Tecnologia - ProGItec" - 30 horas. (MARINHO, 2010). 
E, confirmando, Lucy destacou que:

Quando fomos aprovadas no concurso [ano de 2010], a gente foi lá na Secretaria de Educação escolher a nossa turma, a escola... Nesse momento a gente foi informada que teria uma semana inteira de curso de formação. [...] Comecei a trabalhar, segunda-feira em Tiradentes. Meus primeiros dias de escola, né? [...] recebemos a mensagem de que não haveria mais o curso de formação. [...] Isso foi em 2011. Ai em 2011 passou, passou e não teve. [...] Formação pra gente ter uma visão sobre é... Como a gente poderia utilizar na nossa prática, não tivemos essa formação. [...]. (Lucy, grifos nossos).

Explicitamente, ambas as professoras confirmaram que não foram formadas para trabalhar pedagogicamente com os laptops educacionais no Projeto UCA em Tiradentes. Entretanto, a questão da formação dos professores é ponto fundamental nas políticas educacionais com TDIC, destacando-se como grande desafio. Costa et al. (2008, p. 42) corroboram essa ideia e afirmam que as ações de formação acabam por serem estruturadas " [...] com enfoque predominantemente técnico e desligado dos problemas concretos que a integração curricular das tecnologias implica", sendo:

[...] necessário criar oportunidades para que os professores possam [...] [experimentar as TDIC] [...] em situações concretas de ensino e aprendizagem que lhes permitam ir mais além no conhecimento de estratégias de utilização didática e, desse modo, poderem aumentar também os níveis de confiança com que passarão a encarar essa possibilidade nas suas práticas pedagógicas. (COSTA et al., 2008, p. 42).

Além disso, em Tiradentes, o quadro foi agravado pela falta de informações dadas ao professor a respeito do Projeto: "[...] a gente só chegou a ter contato direto com já... com a ferramenta já de trabalho. Não foi orientado o que que é o PROUCA [na verdade, Projeto UCA]. Né? O que que é um computador por aluno? Qual que era a filosofia desse trabalho? Como que ele deveria ser desenvolvido. [...]". (Bárbara, grifo nosso). E, em conformidade, Lucy afirmou que não lhe havia sido "[...] passado nem o objetivo [...]. Me interessou o projeto. Mas a gente não teve respaldo nenhum da política. A política, parece, não era 
relevada ali dentro da escola. E nem do municipio. [...] A gente não recebeu orientação de forma nenhuma. [...]." (Lucy, grifo nosso).

Assim, a não formação dos professores aliada ao cenário de desinformação descrito pelas professoras afetaram o bom desenvolvimento do Projeto UCA em Tiradentes, constituindo-se como elementos que interferiram na motivação para a efetiva reconfiguração das práticas pedagógicas com as tecnologias. A incursão no campo empírico aliada às informações de Bernardes (2012) e às falas de Bárbara e Lucy indicaram que a apropriação docente das TDIC pela via da formação para o Projeto UCA foi prejudicada, mesmo no que se refere aos estágios iniciais de contato com as tecnologias. Obviamente, isso repercutiu nas ações pedagógicas, que não apresentaram modificações significativas e acabaram por não evidenciar efetiva reconfiguração com o laptop educacional, conforme apresentado no item a seguir.

\section{Prática pedagógica com TDIC}

A análise dos fragmentos pertinentes ao código "Prática pedagógica com TDIC" indicou, fundamentalmente, a ação pesquisa na internet como principal aplicabilidade dos laptops. Isso como uma complementação ao conteúdo programático de sala de aula:

[...] Então, na maior parte das vezes, a gente usava [o laptop] para conteúdo de pesquisas: ciências, geografia, história... E as sequências vinham muito em cima disso. Então, a gente escrevia o conteúdo, que ia ser pesquisado e em qual matéria que a gente estava fazendo. [...] Então assim, para pesquisa era imediato. Instantâneo. [...]. (Bárbara, grifos nossos).

Em conformidade, a professora Lucy também reforçou a utilização das TDIC do Projeto UCA para a busca de conteúdo na internet:

[...] “-Oh professora, vamos pesquisar sobre isso?”. Ai na hora eu falei assim: "-Vamos pesquisar, porque a professora também não sabe". Uma questão diferente, do próprio livro didático. Ai a gente pega a chave [do 
armário que guardava os laptops do Projeto UCA], ligava o computador e pesquisava... [...]. (Lucy, grifos nossos).

De fato, nas situações narradas, é incontestável a eficácia/eficiência do laptop conectado para a localização e acesso à informação. Porém, como ação isolada, a "pesquisa de conteúdo" acaba por apontar aproveitamento parcial dos recursos do laptop, tendo em vista seu potencial de conectividade, mobilidade, imersão e interoperabilidade. (ALMEIDA; PRADO, 2011). Nas ações destacadas por Bárbara e Lucy, é possível perceber práticas que denotam as fases iniciais de seus processos de apropriação das TDIC, limitando-se aos primeiros momentos da dimensão ativa da apropriação (SORJ, 2003) ou, ainda, à etapa da adoção da tecnologia para atividades cotidianas. (SANDHOLTZ; RINGSTAFF; DWYER, 1997).

É fundamental salientar que, ao se considerar as práticas de pesquisa com as TIDC organizadas por Bárbara e Lucy com aproveitamento parcial das tecnologias, não se deseja menosprezar a capacidade profissional das professoras. Ao contrário, considerando as fragilidades que envolveram a implantação do Projeto UCA na Escola Beta (e em Tiradentes como um todo), compreendeu-se que as professoras se desdobraram para prover a utilização daqueles artefatos no limite de suas possibilidades.

Entretanto, não se pode ignorar que, frente a determinado conteúdo, possam emergir oportunidades para a expansão do trabalho pedagógico com a informação e as TDIC, que indicariam estágios mais avançados de apropriação e recairiam na produção de conteúdos. (SORJ, 2003). Nesse sentido, evidencia-se a possiblidade da produção discente no formato digital com o uso de blogs, construção digital de histórias em quadrinhos, estruturação de portfólios, gravação de podcasts, produção de vídeos, organização coletiva de álbuns fotográficos digitais em rede, etc. Essas virtualizações (LÉVY, 1996) não foram constatadas nas falas/experiências das professoras entrevistadas.

Identificou-se também, na codificação dos depoimentos, o discurso que acusava um momento controverso relacionado ao uso do laptop:

[...] E era interessante, porque teve um dia que a Escola nem luz tinha e a gente teve que todo mundo parar todas as atividades para estar usando o laptop. Porque vinha visita. [...] E ai, aconteceu na minha aula, de eles terem de ficar em sala porque as pessoas iam visitar e eles teriam de estar usando o laptop. [...]. (Bárbara). 
Em especial, esse trecho da contribuição de Bárbara à pesquisa remeteu-nos aos estudos das práticas discursivas de James Paul Gee. O autor estadunidense esclarece que, continuamente, (re)construímos nossos mundos pela linguagem em conjunto com ações, interações, sistema de símbolos não linguísticos, objetos, ferramentas, tecnologias, maneiras de pensar/avaliar/sentir e acreditar. Dessa maneira, a linguagem unida a tais aspectos torna-se uma ferramenta de construção do/para o sujeito, em um mundo em que ele atua desempenhando papéis e atividades. (GEE, 1999).

Em termos práticos, Gee (1999) nos indica que, mediante a qualquer enunciação, é importante questionar a maneira como a linguagem é utilizada para construir significados. Nesse sentido, percebemos que Bárbara - no fragmento anterior - assumiu um tom de denúncia da simulação do uso do laptop para terceiros. Ainda mediante a esse episódio narrado por Bárbara, relacionado à hipótese (GEE, 2011) da simulação de uso do laptop para interessados, recorremos à professora Lucy, que também compartilhou seu ponto de vista:

[respondendo consulta por e-mail] Sobre a utilização do laptop na presença de terceiros vivenciei a experiência de ter de utilizá-lo em horário e dia marcado para a demonstração a visitantes - representantes de prefeituras de outras cidades - que queriam conhecer o Projeto. Não denomino como simulação, pois os laptops eram integrados à minha prática. [...]. (Lucy).

Considerando o fragmento discursivo de Lucy, ainda com base em Gee (1999, 2011), questionou-se/analisou-se:

Qual o contexto? Situação: uso do laptop; Local: na escola;

Situação obrigatória/combinada? Sim;

Qual o objetivo? Receber visita;

Segundo Lucy, a situação sugere simulação? Não;

Qual a justificativa de Lucy? Integração do laptop à sua prática pedagógica;

Qual identidade construída/evidenciada no discurso de Lucy? Professora esforçada/competente.

Notadamente, Lucy confirma que as visitas à Escola Beta aconteciam. Seu discurso evidencia obrigatoriedade do uso do laptop em dia e horário marcados, objetivando demonstração para terceiros. Considerando que Lucy afirma integrar os laptops à sua prática, causou-nos estranhamento (GEE, 2011) a necessidade 
de um tempo e horário determinados - quando os alunos deveriam estar utilizando o laptop - para que as visitas pudessem ver uma "demonstração". A contraposição das ideias da professora indica sua preocupação em não ocultar o fato - igualmente experienciado por sua colega Bárbara -, mas também em afirmar sua competência, preservando sua reputação. Ao não considerar a experiência como "simulação", Lucy salienta e valoriza seus esforços na integração do laptop às práticas de ensino.

\section{Reconfiguração da prática pedagógica}

Na pesquisa das práticas pedagógicas com as TDIC junto às professoras, havia especial interesse em ações que indicassem algum tipo de reconfiguração. Nesse sentido, interessavam ações que explicitassem a produção discente com o laptop conectado, orientadas pela(s) professora(as).

Para o grupo de Bárbara, a oportunidade da produção discente com o laptop envolveu a fotografia do patrimônio da cidade:

[...] foi muito interessante, a gente chegou a usar o laptop, por exemplo, numa visita guiada a uma igreja lá, de Santo Antônio, que) os meninos chegavam a ficar boquiabertos. Né?! [...] Então a gente usou o laptop [para o registro fotográfico do patrimônio...] $O$ moço fez uma explanação muito interessante, acho que foi uma das poucas oportunidades de uso real e didático para aquilo [o laptop do Projeto UCA]. Né?! [...]. (Bárbara, grifos nossos).

Lucy também destacou a produção de imagens com o laptop, porém em um projeto que envolvia "visita virtual" ao museu de Cândido Portinari, o conhecimento da obra "Autorretrato", a e fotografia entre pares de alunos e o remix ${ }^{7}$ fotográfico das imagens produzidas.

[...] Primeiro a gente pesquisou Candido Portinari, na própria... Laptop. Ai eles pesquisaram, viajaram no museu, observaram a tela de Portinari - Autorretrato - ai eu falei: “- Agora nós vamos, também, nos tornar

7 O termo é utilizado com o sentido de reelaboração de um produto digital, sugerindo autoria. 
pintores e fazer o nosso autorretrato! Então vocês vão fotografar o rosto de vocês, vão visualizar na tela e desenhar no papel. Mas não vão colocar o nome de vocês não. Não coloca o nome! Só o desenho. ” E eles fizeram. E ai eu misturei [os trabalhos] e pegava o papel e mostrava pra todo mundo: “-De quem que é esse desenho?" Eles desenharam tão perfeito, que todo mundo acertou de todo mundo. E eu coloquei eles longe, pra ninguém ver o do outro. Eu deixei bem distante na sala, pra não ver. Mas eles retrataram de maneira tão real, que dava pra perceber-assim-que era a... a criança. Então eles ficavam assim: maravilhados! Com isso. Né? [...]. (Lucy, grifos nossos).

Considerando a interoperabilidade ${ }^{8}$ (ALMEIDA; PRADO, 2011) dos laptops do Projeto UCA, os dois últimos excertos das entrevistas evidenciam o envolvimento das professoras e, fundamentalmente, dos alunos na produção contextualizada de imagens. No episódio narrado por Bárbara, a prática com o computador ocorreu fora do ambiente escolar, explorando a mobilidade (ALMEIDA; PRADO, 2011) dos equipamentos. Já Lucy utilizou o computador em sua própria sala de aula na escola, porém usufruindo da conectividade (ALMEIDA; PRADO, 2011) do equipamento para contextualizar sua prática. Os dois episódios confluem para um processo de imersão (ALMEIDA; PRADO, 2011) na cibercultura, dada a presença e dado o uso significado do laptop educacional para a produção discente.

Nos episódios narrados, as TDIC mediaram e potencializaram a ação discente, que foi acompanhada pela professora. De maneira significada, aqueles sujeitos fizeram uso das funcionalidades das tecnologias para elaborarem produtos do conhecimento relacionados aos/às seus/suas ambientes/propostas de aprendizagem. Entretanto, ao se considerar o contexto explorado na codificação das "Práticas pedagógicas com TDIC" - embora louváveis -, essas duas situações de uso diferenciado do laptop indicaram uso episódico, o que não sugere $\mathrm{a}(\mathrm{o})$ efetiva(o) formação/desenvolvimento de uma cultura de uso das tecnologias digitais na Escola Beta.

Vale lembrar que, fundamentalmente, o Projeto UCA visou à promoção da inclusão digital pelo contexto escolar, de maneira a desenvolver uma cultura de uso das TDIC voltada para a efetiva participação de professores, alunos e gestores escolares nos processos típicos da cibercultura (LEVY, 1999), realinhando o ensino e a aprendizagem. Até aqui, em sua maior parte, as contribuições de

8 Essa característica do laptop educacional do Projeto UCA relaciona-se à sua interface intuitiva e que oportunizava softwares de fácil operação (editor de texto e manipulação de fotos, por exemplo). 
Bárbara e Lucy evidenciaram experiências, condições e particularidades que se chocaram com o proposto pelo Projeto, inibindo a reconfiguração de práticas e a formação daquela cultura na Escola Beta.

\section{Impacto cultural}

A análise da questão do impacto cultural vivenciado pelo professor em sua adaptação pedagógica para a incorporação de tecnologias às suas práticas está ligada à cultura organizacional escolar e, fundamentalmente, às crenças docentes. (SANDHOLTZ; RINGSTAFF; DWYER, 1997; COSTA et al., 2008; CUBAN, 1993; CHURCHILL, 2005). Assim, tomando em consideração essas prerrogativas teóricas e o contexto de implantação do Projeto UCA em Tiradentes, partiu-se para a análise do impacto cultural vivenciado pelas professoras na migração para o trabalho com as TDIC e dos desdobramentos na atitude pedagógica.

As primeiras evidências identificadas nas entrevistas foi que as professoras demonstraram espanto e ansiedade ao ter de assumir uma sala de aula projetada para um ferramental tecnológico que transcendia à tradição pedagógica: “[...] $O$ computador já existia antes da minha chegada, o Projeto já estava instalado, né?! [...]". (Bárbara). E, como já explicado anteriormente, aquela situação não foi um caso particular daquela professora e envolveu a maior parte dos professores recém-efetivados naquela rede: "[...] acho que foi pra todas: um estranhamento e até receio em usar. Porque até então, nenhuma de nós, tinha tido a experiência de usar a tecnologia dentro da sala de aula [...]". (Lucy, grifos nossos).

É compreensível o sentimento de receio frente ao desafio que as professoras teriam de enfrentar, haja vista o deslocamento em termos de prática pedagógica a ser empreendido. Lucy ainda relatou que havia professora que "[...] não sabia digitar no computador. Agora, você imagina dar uma aula aplicando as tecnologias? Aliando[-as] à sua prática... Então, foi um pouco assim: um receio muito grande [...]". (LUCY, grifo nosso).

Apesar de não ser um processo simplório, as particularidades do contexto de Tiradentes exigiam uma recondução das estratégias de implantação do Projeto de forma a acolher, suportar e incentivar os docentes a vencerem os desafios inerentes àquela proposta (visando à promoção de mudança de crenças). Isso não foi identificado nas contribuições de Bárbara e Lucy.

Esse torvelinho de inseguranças - que vai ao encontro das crenças pedagógicas apontadas por Sandholtz, Ringstaff e Dwyer (1997) - parece ter consolidado mais uma barreira para o bom desenvolvimento do Projeto UCA em Tiradentes. Essa constatação alerta para o fato de que, a depender do contexto, 
os sentimentos associados à adoção das TDIC podem potencializar resistências e aversão à mudança pedagógica.

Ainda considerando as crenças docentes, é importante destacar que os desafios interpostos por um projeto como o UCA, forçosamente, reconduzem os(as) professores(as) à condição de iniciantes. Assim, a já sedimentada tradição pedagógica passa por reveses colocando em risco o equilíbrio do modus operandi escolar: "[...] E muitas vezes os alunos [...] sabiam usar melhor a ferramenta do que a gente, né?! [...]". (Bárbara, grifo nosso).

Os impactos até aqui constatados a partir da Bárbara e da Lucy parecem não convergirem com o propósito de promoção da inclusão digital pelo viés escolar, sugerindo o fracasso do Projeto UCA. Então, cabe sinalizar em que sentido a implementação do Projeto UCA em Tiradentes impactou na apropriação docente das TDIC disponibilizadas. A esse respeito, Lucy nos falou:

[...] A primeira coisa que já foi impactante foi não ter o curso de formação. Só aí já me levou a pensar: "-Que política é essa? Que vai colocar uma coisa nova que a gente não sabe nem o que que é [...] Nem o que que é o objetivo..." [...] A política, parece, não era relevada ali dentro da escola. E nem do município. [...]. A gente não recebeu orientação de forma nenhuma. [...] E colocar lá o laptop é muito fácil. [...] O que que vai ajudar o professor a utilizá-lo? [...] A gente não teve uma ajuda. Nem... Nem... Pedagógica. Nem de nada! [...]. (Lucy).

A professora registrou seu inconformismo por não ter sido devidamente formada para atuar no Projeto e também quanto ao cenário de desinformação que vivenciou. A falta de apoio da retaguarda, também presente em sua fala, reforça o desencontro entre o que estava planejado e aquilo que estava em curso de implementação na cidade. A docente anuncia o aparelhamento da escola e explicita sua indignação quanto à falta de suporte para as ações didáticas com os laptops. Essas impressões também foram partilhadas por sua companheira Bárbara:

[...] Fica complicado se naquele momento eles não te oferecem condições de estar buscando. Então, acho que para tudo ter dado certo, a primeira coisa que precisava ter acontecido, era valorização. Era ter chamado o professor que tava chegando [...] e apresentar o proposto e ir subsidiando ele no percurso. [...]. (Bárbara). 
Esses fragmentos discursivos ratificaram um cenário desfavorável à apropriação docente das TDIC do Projeto UCA em Tiradentes. Impactando nas questões de envolvimento e valorização do professor, na necessidade de formação continuada para as TDIC, na inexistência de suporte e tempo para a instauração de uma perspectiva favorável ao uso dos laptops nas escolas, o desamparo manifestado pelas docentes indiciou: frustração, desmotivação, insegurança e desconforto frente ao Projeto.

Tendo em vista que "[...] o emocional potencializa o campo operacional [...]" e que a “[...] a 'apropriação' das tecnologias passa primeiro pela realização de um desejo" (BORGES, 2009, p. 135), o desprezo desses fundamentos parece ter preterido a apropriação docente das TIDC, afetando a possibilidade de reconfiguração das práticas pedagógicas. Talvez, o impacto cultural vivenciado pelas professoras sequer tenha chegado a envolver - efetivamente - os desafios inerentes às ações pedagógicas com as TDIC (trabalhos coletivo e individual em rede, exploração do potencial comunicativo do ciberespaço e incentivo à autoria, entre outros), contrapondo-se às questões de fundo emocional $/$ motivador docentes, que precedem a sensibilização às práticas.

\section{Considerações finais}

Na busca da compreensão de algumas influências do Projeto (UCA) na apropriação docente das TDIC e nas práticas pedagógicas, este artigo buscou sintetizar as condições contextuais da implantação do Projeto na cidade de Tiradentes e algumas das significações de duas professoras que trabalharam na vigência do mesmo Projeto.

Considerou-se a cibercultura (LÉVY, 1999; LEMOS, 2003, 2008) - ou cultura digital (LEMOS, 2009; LEMOS; LÉVY, 2010) - como contexto geral da investigação e que justifica a necessidade da implementação das políticas de inclusão digital. Mediante a expansão da cibercultura, as políticas públicas de inclusão digital buscam aparelhar as escolas com as TIDC e estimular práticas de ensino e de aprendizagem com as tecnologias mediando as ações/produções docente e discente. Entretanto, embora indispensável, sinaliza-se aqui que a perspectiva da disponibilização e acesso aos artefatos digitais é insuficiente para o desenvolvimento efetivo da cultura digital no âmbito escolar. Além do aparelhamento das escolas e do uso meramente instrumental, considera-se essencial a participação ativa, autônoma, consciente e ética na produção da cultura contemporânea, o que reflete o uso significado das tecnologias digitais. 
As contribuições das professoras de Tiradentes nos permitiram inferir que a apropriação docente das TDIC e respectiva reconfiguração pedagógica são condicionadas: pelo acesso satisfatório às TDIC, pelo suporte técnico e pedagógico constantes e pela formação continuada dos professores, que oportunize experiências contextualizadas de uso pedagógico das tecnologias. Além disso, outros dois fatores pareceram determinantes nessa dinâmica: o tempo e a revisão das crenças pedagógicas docentes.

A reconfiguração pedagógica com TDIC não é alcançada por decreto. Assim, a mudança pedagógica com TDIC está atrelada a uma perspectiva de longo prazo, o que pode oportunizar a conscientização docente quanto às potencialidades das tecnologias. Além disso, a revisão das crenças pedagógicas constitui um determinante na apropriação docente das TDIC. Essa inferência parte da constatação de que a presença das tecnologias digitais desestabiliza o modus operandi escolar, gerando resistências. Vencer obstáculos - de ordens técnica, logística, pedagógica e cultural - implica a necessidade de mobilização e gosto docente (BORGES, 2009) para a apropriação dessas tecnologias.

\section{REFERÊNCIAS}

ALMEIDA, M. E. B.; PRADO, M. E. B. B. (Org.). O Computador Portátil na Escola. São Paulo: Avercamp, 2011.

BARDIN, L. Análise de conteúdo. Lisboa: Edições 70, 1977.

BERNARDES, A. T. Relatório sintese do contrato UFOP/FEOP. Cidades Digitais: utilização de serviços através da tecnologia digital. Ouro Preto: Ministério da Educação, 2012.

BORGES, M. A. F. Apropriação docente das tecnologias de informação e comunicação pelos gestores educacionais. 321 f. Tese (Doutorado em Educação) - Pontifícia Universidade Católica de São Paulo, São Paulo, 2009.

CHURCHILL, D. Teachers' private theories and their design of technology-based learning. British Journal of Educational Technology, v. 37, n. 4, p. 559-576, 2005.

COSTA, F. A.; RODRIGUES, A.; PERALTA, H.; RAMOS, J. L.; SEBASTIÃO, L.; MAIO, V.; DIAS, P.; GOMES, M. J.; OSÓRIO, A. J.; RAMOS, A.; VALENTE, L. Competências TIC. Estudo de Implementação. Lisboa, Portugal: Gabinete de Estatística e Planejamento da Educação (GEPE) / Ministério da Educação, 2008. v. 1.

CUBAN, L. Computers meet classroom: classroom wins. Teachers College Record, $\mathrm{n}$. 95, p. 185-210, 1993. 
ESCOLA MUNICIPAL. Projeto Político Pedagógico. Tiradentes, 2011.

FORMAÇÃO BRASIL. Disponível em: < https://issuu.com/marinhos/docs/formacaobrasil_modulo1_parte1>.Acesso em: 12 ago. 2014a.

FORMAÇÃO BRASIL. Disponível em: < https://issuu.com/marinhos/docs/formacaobrasil_modulo1-parte2>. Acesso em: 13 mar. 2014b.

GEE, J. P. An Introduction To Discurse Analysis: theory and method. New York: Routledge, 1999.

GEE, J. P. How to do discourse analysis: a toolkit. New York: Routledge, 2011.

LEMOS, A. Cibercultura: alguns pontos para compreender a nossa época. In: LEMOS, A.; CUNHA, P. (Org.). Olhares sobre a cibercultura. Porto Alegre: Sulina, 2003. p. 11-23.

LEMOS, A. Cibercultura. Tecnologia e Vida Social na Cultura Contemporânea. Porto Alegre: Sulina, 2008.

LEMOS, A. Depoimento. Entrevista concedida a Rodrigo Savazoni e a Sergio Cohn. Rio de Janeiro: Cultura digital.br, 2009.

LEMOS, A.; LÉVY, P. O futuro da internet: em direção a uma ciberdemocracia planetária. São Paulo: Paulus, 2010.

LÉVY, P. O que é o virtual. São Paulo: Editora 34, 1996.

LÉVY, P. Cibercultura. São Paulo: Editora 34, 1999.

MARINHO, S. P. UCA Minas: Programa Um Computador por Aluno. Belo Horizonte, 19 jul. 2010. Disponível em: <http://goo.gl/JqPUcM>. Acesso em: 05 nov. 2013.

SANDHOLTZ, J. H.; RINGSTAFF, C.; DWYER, D. C. Ensinando com tecnologias: criando salas de aula centradas nos alunos. Porto Alegre: Artes Médicas, 1997.

SORJ, B. Brasil@povo.com: a luta contra a desigualdade na sociedade da informação. Rio de Janeiro: J. Zahar; Brasília: Unesco, 2003.

Texto recebido em 30 de março de 2016. Texto aprovado em 30 de abril de 2016. 